\title{
ROLE OF INFORMATION AND COMMUNICATION TECHNOLOGIES IN AGRICULTURAL EXTENSION; COMPARATIVE STUDY OF PRESENT AND FUTURE ASPECTS IN DISTRICT KHANEWAL
}

\section{*RANA HAA, IFTIKHAR M, CHAUDHRY KM, *USMAN M, MAZHAR F}

\author{
Institute of Agricultural Extension, Education and Rural Development, University of Agriculture, Faisalabad, \\ Punjab, Pakistan \\ Corresponding author: malikusmanuaf@gmail.com
}

(Received, $5^{\text {th }}$ June 2020, Revised $22^{\text {nd }}$ June 2020, Published $25^{\text {th }}$ June 2020)

\begin{abstract}
Agricultural extension is the main driving force in technology transfer from researcher to the end users. But it is facing tremendous challenges due to lack of government interest and financial resources. The prominent issue of agricultural extension is to cover huge number of small farmers in scattered form. Information and Communication Technologies can play a vital role to resolve this issue. The present study was conducted in Tehsil Khanewal to evaluate the type of ICTs used by farmers and their contribution for the development of agricultural extension in future. Data were collected with the help of well-structured interview schedule from 234 farmers and collected data were statistically analyzed with the help of computer software Statistical Package for Social Sciences (SPSS). Higher variation was recorded which was ranging from (2.9\%) to (66.6\%) in case of ICTs as a source of agricultural information. The most prominent ICTs device used as a source of agricultural information was TV with exactly two third (66.6\%) of the total respondents followed by mobile phone with slightly less than TV (63.6\%). Use of Agri. websites and mobile Apps for agriculture consultancy were below bottom line with 4.7\% and 2.9\%, respectively. Mobile phone was on top ranking with weighted score $=959$ and mean value $=4.12$, as an effective tool for getting agricultural information in future. Agri. helpline was on the second number with weighted score $=875$ and mean value $=3.74$. It was suggested from our study that there is a need to create awareness among the farmers about the use of ICTs. Farmers must be educated by the extension staff about the use of internet and agriculture mobile apps for fetching the information and finding the solution of the problems which they face in fields.
\end{abstract}

Keywords: Agricultural Extension, ICTs, Mobile phone, Television, Computer, Internet, Radio

\section{Introduction}

Agriculture is a powerful engine of Pakistan's economy contributing $18.95 \%$ in total gross domestic product (GDP). This sector has a significant importance in Pakistan, providing food to the fast growing population of the country. Govt. of Pakistan, 2018-19). Despite the significant importance to the income, food security, imports, exports and growth of agriculture has been distressed from sudden decline. From the past two decades growth in the crop sector has been falling down (Anonymous, 2013). Diffusion of agricultural knowledge and information in the rural areas is crucial to crop productivity because it is the only way through which farmers can learn about new technologies and farm practices which can increase their crop yield (Onasanya et al., 2011). Agricultural extension services are usually established to improve the knowledge and skills of farmers on farming practices and make their attitude positive towards agricultural innovations (Shalaby et al., 2011). Public and private extension services (especially in many developing countries) are facing tremendous challenges not only to reach the several and diverse farmers that require their services, but to reach them when and where they need the services. The reasons behind these challenges are clear: small farms with limited resources; large number of clients; poor infrastructure; high rates of farmer illiteracy; extension workers with variable technical, diagnostic and extension skills and poorly funded extension systems (Bell and Payne, 2014). Extension to farmer ratio in Pakistan was 1: 6,881 as against 1: 800 according to the World Bank recommendations. High extension to farmer ratio results in poor delivery of massage from extension worker to the farmers (Chukwu et al., 2013).

Information and Communication Technologies (ICTs) refer to a system which produce, store and retrieve digital files. The penetration of ICTs is

[Citation: Rana H.A.A, Iftikhar, M., Chaudhry, K.M., Usman, M., Mazhar, F. (2020). Role of Information and Communication Technologies in Agricultural Extension; Comparative Study of Present and Future Aspects in District Khanewal. Biol. Clin. Sci. Res. J., 2020: 12 doi: https://doi.org/10.54112/bcsrj.v2020i1.12]. 
increasing rapidly now a days it is just ready to touch the bottom of the whole world (PTA, 2015). ICTs can play a vital role to inform the farmers in the situation of urgency and emergency. Farmers can be informed quickly and swiftly about diseases and pest control, flood, changing weather (Muhammad, 2005). Now, the question is that: how can under developed countries correctly use ICTs to get benefit from the global knowledge? It is a clear cut $100 \%$ sure fact that ICTs itself cannot improve the communication, it only facilitate communication. It is essential to eradicate the hurdles faced by the rural people and provide them basic setup in rural community to enable ICTs to spread, which would make them a part of socio economic development strategies of their areas (Lee and Lee, 2004).

\section{Materials and methods}

Study was conducted in District Khanewal. District Khanewal consists of four Tehsils, namely, Khanewal, Mian Channu, Kabir wala, Jahaniyan. Tehsil Khanewal was selected purposively as ease for the researcher. Tehsil Khanewal consist of 2 markaz i.e. Kacha Khuh and Khanewal. One markaz was selected randomly. A sampling frame was constructed by enlisting all the farmers who were using ICTs in that research area. There were 600 farmers who were using ICTs. A sample of 234 respondents was selected by using survey software i.e. surveysystem.com with confidence level $95 \%$ and confidence interval 5\%. Then selected sample has been randomized through web based survey i.e. randomizer.org. By randomizing the sample size, a list was generated ranging from 1-600 respondents. An interview schedule was designed then this validated and pre tested interview schedule translated into local language for respondents. Qualitative data were collected with probing and group discussion technique. Quantitative data were collected with the help of designed close ended questions. Data were arranged to analyze it with the help of statistical software and programs. As our research follows social science, SPSS was used for data analysis.

\section{Results and discussion}

\section{Distribution of respondents according to the type} of ICT used as a source of information

ICTs provides information and entertainment (Shamsi, 2006). Different farmers use different ICT tools as a source of information. Each farmer do not use every source of ICT to get information. Use of it depend on the availability of specific ICT tool and awareness to use it for the purpose of as a source of information.

Table.1 Distribution of respondents according to the type of ICT used by the farmers $\quad n=234$

\begin{tabular}{|l|l|l|}
\hline Source of information & Frequency & Percentage \\
\hline TV & 156 & 66.6 \\
\hline Radio & 12 & 5.1 \\
\hline Mobile phone & 149 & 63.6 \\
\hline Mobile apps & 7 & 2.9 \\
\hline Agri. help line number & 71 & 30.3 \\
\hline Internet/ Agri. Website & 11 & 4.7 \\
\hline
\end{tabular}

The data given in table 1 indicate that in case of ICT as a source of information, a great variation was on the seen ranging from 2.9 percent to 66.6 percent.

The most prominent ICT device used as a source of agricultural information was TV with the score of exactly two third $(66.6 \%)$ of the total respondents followed by mobile phone with slightly less than TV $(63.6 \%)$. A satisfactory response in case of help line was also there as (30.3\%) respondents receive information. It was clear that use of radio in modern era was not common. Only fraction $(5.1 \%)$ of the respondent get information by using radio. Use of Agri. websites and mobile Apps for agriculture consultancy was also below bottom line with $(4.7 \%)$ and $(2.9 \%) .(16.2 \%)$ were using other ICT devices such as recorded video clips, audio video messages in CDs and DVDs as a source of information.

Only TV and mobile phone were efficiently used by the respondents. Same rustle was observed by the others. Khan (2010) discussed that the most prominent electronic Device was TV $(66.06 \%)$ followed by mobile phone (46.36\%) as a source of agricultural information. The results are contradictory to those of (Okwu et al.2007) where majority (69\%) of the respondents used radio sets for agricultural information. The finding of quantitative data were supported with the qualitative as one of the respondents said that "mobile phone had every facility in it such as audio player, video player, recording tool, FM, calendar, watch, torch, calculator, games and internet browser $(2 G, 3 G$ supported) then why we use separate radio, torch light, watch or torch light".

Getting deep insight, the use of ICT for getting Agri. information was not encouraging. The general perception of ICT seems entirely different from the ground reality. The range of using ICT specifically in obtaining Agri. information was from very low to low levels.

It may be concluded that farmers did not give due consideration to ICT in getting the Agri. information. The situation demands for more concrete effort in this regard to develop urge for using it as valuable sources of Agri. information. Farmers are the end user of any type of technology. It was deeply required to ask the farmer about the use of ICTs as a

[Citation: Rana H.A.A, Iftikhar, M., Chaudhry, K.M., Usman, M., Mazhar, F. (2020). Role of Information and Communication Technologies in Agricultural Extension; Comparative Study of Present and Future Aspects in District Khanewal. Biol. Clin. Sci. Res. J., 2020: 12 doi: https://doi.org/10.54112/bcsrj.v2020i1.12]. 
source of agricultural information. The data collected from the respondents is shown below.

Comparison of different ICT tools used as a source of agricultural information in present and future

Table 2. (Present use)

\begin{tabular}{|l|c|c|c|c|c|c|c|c|c|}
\hline ICTs & $\mathbf{1}$ & $\mathbf{2}$ & $\mathbf{3}$ & $\mathbf{4}$ & $\mathbf{5}$ & Score & Ranking & Mean & S.D \\
\hline TV & 0 & 12 & 44 & 91 & 87 & 955 & 1 & 4.11 & 0.74 \\
\hline Mobile phone & 2 & 13 & 48 & 93 & 78 & 934 & 2 & 4.08 & 0.72 \\
\hline Agri. help line number & 112 & 25 & 45 & 17 & 30 & 515 & 3 & 2.98 & 1.01 \\
\hline Internet/ Agri. Website & 169 & 35 & 12 & 6 & 12 & 359 & 4 & 2.01 & 1.34 \\
\hline Radio & 178 & 39 & 11 & 5 & 1 & 314 & 5 & 1.88 & 1.63 \\
\hline Mobile apps & 225 & 3 & 1 & 2 & 3 & 257 & 6 & 1.42 & 1.99 \\
\hline
\end{tabular}

1. Very low 2. Low 3. Medium

To get a clear picture of the response the data were rearranged to calculate the score, ranking, Mean and S.D. The data presented in table .2 declared that TV was on the top of the table as a source of information in present situation with the score of 955 and its mean value was 4.11 , followed by mobile phone with the score 934, slightly less than of the TV. Respondents further explained that use of mobile

Table 3. (Future use)

The respondents were asked about the future of ICTs in agriculture to get information or business development. Over all response claim that it has a bright future. The collected data are presented in the following table after analysis. $\mathbf{n = 2 3 4}$

\begin{tabular}{|l|c|c|c|c|c|c|c|c|c|}
\hline ICTs & $\mathbf{1}$ & $\mathbf{2}$ & $\mathbf{3}$ & $\mathbf{4}$ & $\mathbf{5}$ & Score & Ranking & Mean & S.D \\
\hline Mobile phone & - & - & 55 & 96 & 83 & 959 & 1 & 4.12 & 0.760 \\
\hline Agri. Helpline number & - & 17 & 77 & 90 & 50 & 875 & 2 & 3.74 & 0.877 \\
\hline Mobile apps & 3 & 23 & 75 & 92 & 42 & 852 & 3 & 3.62 & 0.929 \\
\hline TV & 8 & 27 & 85 & 71 & 43 & 816 & 4 & 3.49 & 1.028 \\
\hline Internet / Agri. website & 10 & 27 & 81 & 77 & 39 & 810 & 5 & 3.46 & 1.036 \\
\hline Radio & 230 & 2 & 2 & 0 & 0 & 240 & 6 & 1.39 & 1.90 \\
\hline
\end{tabular}

1. Very low 2. Low 3. Medium 4. High

The data presented in table $\mathbf{3}$ reflected that mobile phone was on top in ranking with (score $=959 \&$ mean=4.12) as an effective tool for getting agricultural information in future. Agri. helpline was on the second number with (score $=875 \quad \&$ mean=3.74). The mean value of mobile phone (4.12) fell between very high (5) to high (4) but tends towards high. Mean value fell between medium to high but tends towards the high in case of Agri. helpline. TV and Internet/ agri. websites were ranked $3^{\text {rd }}$ and $4^{\text {th }}$ with (score $=852 \&$ mean 3.62 and score $=816 \&$ mean 3.49$)$ respectively with (score $=810 \&$ mean=3.46). Scope of radio was near about zero, its reason was the entry of TV, mobile phones and internet. Mean value indicate that it's bending towards very low. It was observed that future of mobile phone and Agri. helpline were brighter because of two way flow of information. Surprisingly TV was at no. 4 in the list. Farmer think the massages delivered on TV were common or just for the phone in agriculture was generally to talk with fellow farmers or middle man/ Dealer for marketing of production and input availability. The response of Agri. help line numbers and Internet/Agri. Websites was bit low than satisfactory with the score of 515 and 359. Use of Agri. websites and mobile Apps for agriculture consultancy was also below bottom line
4. High

publicity of their products further more they cannot enquire about anything on the TV.

The comparison of present and future scores of different ICT tolls (Figure 1) give an idea that many tools will be used extensively in the future. The differences of Mobile Apps score is higher than all the other tools, followed by computer and agricultural websites. Agricultural help line also have good future. In farmers view mobile phone users for agricultural information were at peak that time, they believe that users will increase marginally in number but their using trends will change. The user of TV for agricultural consultancy were higher than all the others ICT tools but it is losing its charm due to the improvements and accessibility of smart phone and internet. TV also have a downside due to the one way flow of information. Respondents quoted the example of radio, a popular media used in nineties and before. But due to the absence of visual facilities it started to loss its popularity and TV replace it more efficiently.

[Citation: Rana H.A.A, Iftikhar, M., Chaudhry, K.M., Usman, M., Mazhar, F. (2020). Role of Information and Communication Technologies in Agricultural Extension; Comparative Study of Present and Future Aspects in District Khanewal. Biol. Clin. Sci. Res. J., 2020: 12 doi: https://doi.org/10.54112/bcsrj.v2020i1.12]. 
Results claim that radio was at the bottom and will go deeper in future.

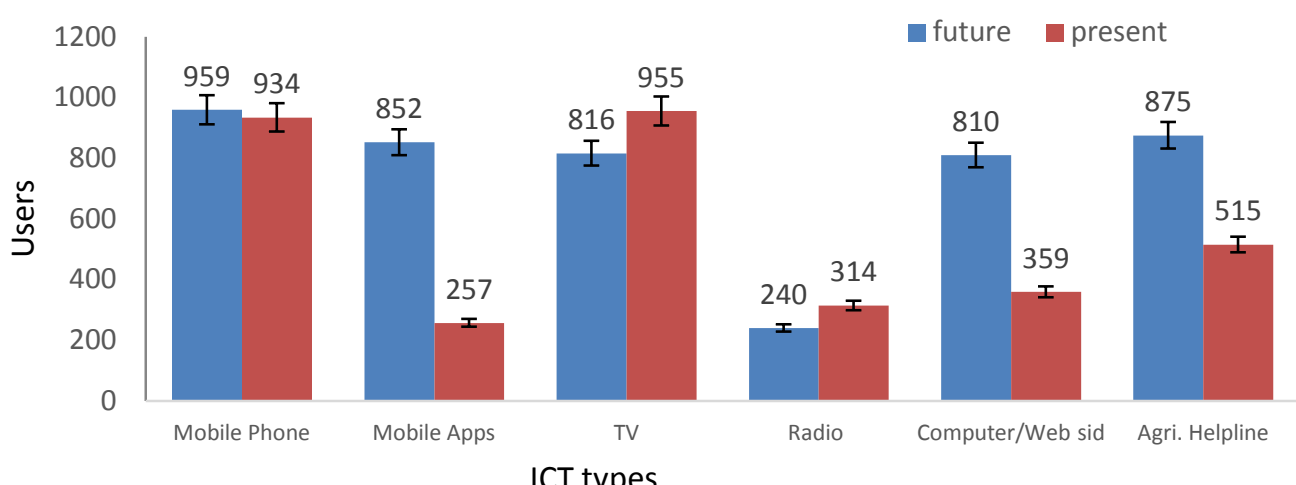

Figure 1. Comparison among various ICT types

\section{Conclusion}

Use of ICT in agricultural extension is a hot talk in the modern era. The purpose of this study was to determine the real future of ICT in agricultural extension. It was cheeked what type of ICT they used most of the time to get information and what they think about the future of it in extension field. At this time it was perceived that TV and mobile phone are commonly used by the farmers to get information and consultancy. Farmers believe that future of agricultural websites and agricultural Mobile Apps is more glooming than other due to the access of smart phone and internet. In farmer view use of mobile phone could be most effective due to its multi functioning properties.

\section{Conflict of interest}

The authors declared the absence of any potential conflict of interest.

\section{References}

Bell, M.A. and J. Payne. (2014). ICT in Extension. IPO Information for impact series. IPO. UC Davis.

Chukwu G.O., T.U. Madu, E.C. Chinaka and N.H. Anyaegbunam. (2013). Penologists approach to agro-technology transfer: case study of Ikwuano Abia State Nigeria. African Journal of Agriculture Research, 2: 148-152.

Govt. of Pakistan, (2013). Economic Survey of Pakistan. Federal Bureau of Statistics, Statistics Division, Islamabad

Govt. of Pakistan, (2018-19). Economic Survey of Pakistan. Federal Bureau of Statistics, Statistics Division, Islamabad

Khan, G.A. (2010). Present and prospective role of electronic media in the dissemination of agricultural technologies among farmers of the Punjab, Pakistan. Ph.D. Thesis, Department of
Agricultural Extension, Univ. of Agri., Faisalabad.

Lee, J.D. and H. Lee. (2004). Economic analysis of community e-centers for rural development. Asian Development Bank Regional Workshop, Bali, Indonesia.

Muhammad, S. (2005). Agricultural extension: strategies and skills. Unitech communication, Faisalabad, Pakistan.

Okwu, O.J., A.A. Kuku, and J.I. Aba, 2007. An assessment of use of radio in agricultural information dissemination: a case study of radio Benue in Nigeria. African Journal of Agriculture Research, 2: 014-018.

Onasanya S.A., R.A Shehu, O.O. Ogunlade, A.L. Adefuye. (2011). Teacher's awareness and extent of utilisation of information and communication technologies for effective science and health education in Nigeria. Singapore Journal of Science and Research, 1: 49-58.

Pakistan Telecommunication Authority. (2015). Annual Report 2014-15. http://www.pta.gov.pk/index.php?option=com 1 ontent\&view=article\&id=361\&Itemid=590.

Shalaby, M. Y., K. H. Al-Zahrani, M. B. Baig, G. S. Straquadine and F. Aldosari. (2011). Threats and challenges to sustainable agriculture and rural development in Egypt: Implications for agricultural extension. Journal of Animal and Plant Science.. 21: 581-588.

Shamsi, A.N. (2006). Mass Media in New World Oder. SBS Publisher \& Distributors P. Ltd, New Delhi. 


\section{(c) (1) 8}

Open Access This article is licensed under a Creative Commons Attribution 4.0 International License, which permits use, sharing, adaptation, distribution and reproduction in any medium or format, as long as you give appropriate credit to the original author(s) and the source, provide a link to the Creative Commons licence, and indicate if changes were made. The images or other third party material in this article are included in the article's Creative Commons licence, unless indicated otherwise in a credit line to the material. If material is not included in the article's Creative Commons licence and your intended use is not permitted by statutory regulation or exceeds the permitted use, you will need to obtain permission directly from the copyright holder. To view a copy of this licence, visit http://creativecommons.org/licen ses/by/4.0/.

(C) The Author(s) 2021

[Citation: Rana H.A.A, Iftikhar, M., Chaudhry, K.M., Usman, M., Mazhar, F. (2020). Role of Information and Communication Technologies in Agricultural Extension; Comparative Study of Present and Future Aspects in District Khanewal. Biol. Clin. Sci. Res. J., 2020: 12 doi: https://doi.org/10.54112/bcsrj.v2020i1.12]. 